\title{
A Spectroscopic Study of Oils Used in Oil-Extended Rubber ${ }^{1}$
}

\author{
Frederic J. Linnig and James E. Stewart
}

\begin{abstract}
Knowledge of the composition of oils used in oil-extended rubber is useful in specifying oil types and in understanding the properties of the oil-rubber master batches. In this work, elucidation of structure has been attempted by a comparison of infrared spectra between 2 and 15 microns of two series of oil fractions obtained by basically different methods. Fractions of a number of different oils or oil distillates were studied. The spectra were compared with reference to the method of separation and in some cases to the physical and chemical properties of the fractions. There are marked similarities between certain of the fractions separated by the two methods. However, the study indicates a variability of structural types from one oil to another. This is especially true for the more polar fractions. It is suggested that this varability, especially with respect to polar groups and other structures leading to active hydrogens, could account for the observed variability in the aging properties of master batches containing different oils or oil fractions.

Spectra were also obtained of a few typical fractions in the ultraviolet range between 210 and 340 millimicrons and in the far infrared between 15 and 40 microns.
\end{abstract}

\section{Introduction}

It has become common practice during the last few years to combine petroleum distillates in emulsion form with GR-S synthetic rubber latex to vield, on coagulation, what is termed an "oil-rubber master batch" or an "oil-extended GR-S".

The GR-S used is a copolymer of butadiene and styrene that had been polymerized to a highmolecular weight. Thus, the rubber itself is much stiffer than usual. As a result, the final homogeneous mixture of oil and rubber has properties quite similar to the lower molecular weight GR-S without the added oil. The added oil extends the available supply of rubber, and because of its very low cost, reduces the price of the final products. The oils used are predominantly the resinous portions of high-boiling petroleum distillates from which the paraffinic material, employed as lubricating oil, has been largely extracted. They are, or course, highly complex mixtures of many compounds widely different in type, consisting of more than 20 carbon atoms.

It is well recognized that the physical properties and the compounding and aging characteristics of the oil-extended polymers depend, to some extent, on the type of oil used $[9,14,25,26,27,28,29,34,35$, $36,37,38,39,40,42]{ }^{2}$ In order to facilitate the specification of oil types, a number of methods of analysis have been developed, one based on acid extraction and physical properties $[25,27]$ and several on chromatographic techniques $[9,13,18]$. In one chromatographic method, ring types and carbon types are identified from physical properties [18].

The method devised by Rostler and Sternberg $[25,27]$ depends on the separation of the oil into sxi fractions extracted from the pentane soluble portion of the sample by anhydrous hydrogen chloride and

1 This work was presented, in part, at the Pittsburgh Conference on Analytical Chemistry and Applied Spectroscopy, Pittsburgh, Pa., March 1955

${ }_{2}^{2}$ Figures in brackets indicate the literature references at the end of this paper. by sulfuric-acid solutions of different strengths. This procedure has been generally used in classifying oil types. It has, however, been shown that some properties, such as aging of master batches containing certain of these fractions, depends on the oil from which the fraction came [36].

A method developed at the National Bureau of Standards by Termini and Glasgow [13] depends on the chromatographic separation of the oil into five fractions, using silica gel as the adsorbent and eluting the material successively with two portions of pentane, followed by benzene, carbon tetrachloride, and ethanol.

Knowledge of the composition of the oil fractions themselves and the variations in the composition of fractions obtained from different oils should be helpful in further characterizing these materials and in explaining observed variations in the properties of rubber containing them. The present work constitutes a part of the program undertaken at the National Bureau of Standards to elucidate the chemical composition of extender oils. In this study, infrared and, to a lesser extent, ultraviolet spectroscopy have been used to accomplish the following: (1) To compare the over-all spectroscopic features of the fractions obtained by the method of Termini and Glasgow with the fractions of a single oil obtained by the method of Rostler and Sternberg; (2) to indicate molecular types in the fractions; (3) to show how these molecular types may vary from one oil to another; and (4) to explore the correlation between reported performance tests and structural groups present in the different oil fractions. To this end, infrared spectra were obtained on a number of fractions furnished by Rostler. They represent a number of the fractions obtained by acid extraction of three different distillates of the same crude oil. Spectra were also obtained on fractions of six different oils from various parts of the country, separated chromatographically by Termini and Glasgow [13], and furnished by them. 
The chemical and physical properties of the particular fractions separated by the acid-extraction method and used in this study are presented and discussed in a paper by Rostler and White [29]. For convenience, these fractions are described in this paper in terms of the familiar analytical method $[25,27]$ rather than the modified procedure actually used in preparing them [29]. Values for the refractive index of the fractions separated chromatographically were furnished by Termini and Glasgow [13]. These two sets of data are presented in tables 1 and 2 , respectively. The analysis of the six different oils by the two methods is given in table 3 . The data for the chromatographic procedure were furnished by Termini and Glasgow [13] and those for the acid extraction procedure by Rostler [24].

TaBLE 1. Physical properties and composition of oil fractions separated by acid-extraction method

Data of Rostler and White [29]

\begin{tabular}{|c|c|c|c|c|c|c|c|c|c|c|}
\hline \multirow{2}{*}{ Oil Fraction 1} & \multirow{2}{*}{$\begin{array}{l}\text { Designation of R } \\
\text { and W [29] }\end{array}$} & \multirow{2}{*}{$\begin{array}{c}\text { Density, } \\
d_{4}^{20}\end{array}$} & \multirow{2}{*}{$\begin{array}{l}\text { Refractive } \\
\text { index, }{ }^{25}{ }_{D}^{25}\end{array}$} & \multirow{2}{*}{$\begin{array}{l}\text { Molecular } \\
\text { weight }\end{array}$} & \multicolumn{5}{|c|}{ Elementary composition } & \multirow{2}{*}{$\begin{array}{l}\text { Carbon- } \\
\text { hydrogen } \\
\text { weight } \\
\text { ratio }\end{array}$} \\
\hline & & & & & $\mathrm{C}$ & $\mathrm{H}$ & $\mathrm{N}$ & $\mathrm{S}$ & Total & \\
\hline \multicolumn{11}{|c|}{ DISTILLATE 1} \\
\hline $\begin{array}{l}\text { First acidaffins (a) } \\
\text { Second acidaffins (a) } \\
\text { First acidaffins (b) } \\
\text { Second acidaffins (b) } \\
\text { Nitrogen bases, group I } \\
\text { Nitrogen bases, group II }\end{array}$ & $\begin{array}{l}985-\mathrm{A}-(1) \\
985-\mathrm{A}-\mathrm{II}(1) \\
985-\mathrm{A}-(2) \\
985-\mathrm{A}-\mathrm{II}(2) \\
\text { N-960-I } \\
\text { N-960-II }\end{array}$ & $\begin{array}{l}1.002 \\
0.988 \\
1.054 \\
1.010 \\
1.025 \\
1.018\end{array}$ & $\begin{array}{l}\text { 1. } 5780 \\
\text { 1. } 5612 \\
\text { 1. } 6036 \\
\text { 1. } 5796 \\
\text { 1. } 5698 \\
\text { 1. } 5578\end{array}$ & $\begin{array}{l}226 \\
233 \\
250 \\
239 \\
269 \\
267\end{array}$ & $\begin{array}{l}\% \\
88.95 \\
89.73 \\
89.49 \\
89.59 \\
84.68 \\
83.81\end{array}$ & $\begin{array}{r}\% \\
9.14 \\
9.88 \\
8.75 \\
9.25 \\
9.75 \\
10.08\end{array}$ & $\begin{array}{r}\% \\
0.04 \\
.02 \\
.06 \\
.02 \\
4.36 \\
3.81\end{array}$ & $\begin{array}{l}\% \\
1.08 \\
0.66 \\
1.01 \\
1.01 \\
0.70 \\
.94\end{array}$ & \begin{tabular}{r}
\multicolumn{1}{c}{$\%$} \\
99.21 \\
100.29 \\
99.31 \\
99.87 \\
99.49 \\
98.64
\end{tabular} & $\begin{array}{r}9.732 \\
9.082 \\
10.257 \\
9.685 \\
8.685 \\
8.314\end{array}$ \\
\hline \multicolumn{11}{|c|}{ DISTILLATE 3} \\
\hline $\begin{array}{l}\text { Paraffins (a) } \\
\text { Paraffins (b) } \\
\text { First acidaffins, } \\
\text { Second acidaffins } \\
\text { Nitrogen bases, group I } \\
\text { Nitrogen bases, group II }\end{array}$ & $\begin{array}{l}\mathrm{P}-940 \\
\mathrm{P}-955 \\
973-\mathrm{A} \\
982-\mathrm{A}-\mathrm{II} \\
\mathrm{N}-947-\mathrm{I} \\
\mathrm{N}-947-\mathrm{II}\end{array}$ & $\begin{array}{r}0.910 \\
.891 \\
1.055 \\
1.017 \\
1.061 \\
1.027\end{array}$ & $\begin{array}{l}\text { 1. } 4921 \\
\text { 1. } 4833 \\
\text { 1. } 6172 \\
\text { 1. } 5854 \\
\text { 1. } 6087 \\
\text { 1. } 5608\end{array}$ & $\begin{array}{l}373 \\
408 \\
298 \\
303 \\
271 \\
366\end{array}$ & $\begin{array}{l}86.50 \\
86.28 \\
89.53 \\
88.84 \\
86.12 \\
83.98\end{array}$ & $\begin{array}{r}13.46 \\
13.43 \\
8.82 \\
9.50 \\
8.89 \\
10.42\end{array}$ & $\begin{array}{l}0.17 \\
.05 \\
3.83 \\
3.18\end{array}$ & $\begin{array}{l}1.35 \\
1.02 \\
0.47 \\
.53\end{array}$ & $\begin{array}{l}99.96 \\
99.71 \\
99.87 \\
99.41 \\
99.31 \\
98.11\end{array}$ & $\begin{array}{r}6.426 \\
6.424 \\
10.151 \\
9.352 \\
9.687 \\
8.060\end{array}$ \\
\hline \multicolumn{11}{|c|}{ DISTILLATE 4} \\
\hline $\begin{array}{l}\text { First acidaffins } \\
\text { Second acidaffins } \\
\text { Nitrogen bases, group I } \\
\text { Nitrogen bases, group II }\end{array}$ & $\begin{array}{l}980-\mathrm{A} \\
986-\mathrm{A}-\mathrm{II} \\
\mathrm{N}-956-\mathrm{I} \\
\mathrm{N}-956-\mathrm{II}\end{array}$ & $\begin{array}{l}1.053 \\
1.017 \\
1.079 \\
1.007\end{array}$ & $\begin{array}{l}\text { 1. } 6152 \\
\text { 1. } 5879 \\
\text { 1. } 614 \\
\text { 1. } 565\end{array}$ & $\begin{array}{l}335 \\
348 \\
332 \\
390\end{array}$ & $\begin{array}{l}89.09 \\
88.68 \\
87.34 \\
84.70\end{array}$ & $\begin{array}{r}8.84 \\
9.60 \\
8.61 \\
10.38\end{array}$ & $\begin{array}{r}0.02 \\
.03 \\
2.91 \\
2.54\end{array}$ & $\begin{array}{l}1.14 \\
1.05 \\
0.68 \\
.69\end{array}$ & $\begin{array}{l}99.09 \\
99.36 \\
99.54 \\
98.31\end{array}$ & $\begin{array}{r}10.078 \\
9.238 \\
10.144 \\
8.160\end{array}$ \\
\hline
\end{tabular}

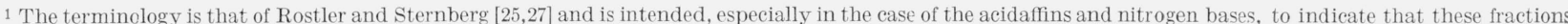
are concentrates of the designated component (see group analysis of Rostler and White [29] table II).

TABLE 2. Index of refraction of oil fractions separated chromatographically

(Data of Glasgow and Termini [13])

\begin{tabular}{|c|c|c|c|c|c|c|}
\hline Oil fraction & $\begin{array}{c}\mathrm{I} \\
\text { Circos } 1 \\
2 \times \mathrm{H}\end{array}$ & $\begin{array}{c}\text { II } \\
\text { Sundex } \\
53\end{array}$ & $\begin{array}{c}\text { III } \\
\text { SPX } 97\end{array}$ & $\begin{array}{c}\text { IV } \\
\text { Philrich } \\
5\end{array}$ & $\underset{\substack{\text { Vutrex } \\
20}}{\text { D }}$ & $\begin{array}{c}\text { VI } \\
\text { Califlux } \\
\text { TT }\end{array}$ \\
\hline First pentane & 1. 4882 & 1. 4805 & 1. 4800 & 1. 4845 & 1.4915 & 1. 4923 \\
\hline Second pentane & 1.5017 & 1. 4993 & 1. 4995 & 1. 5015 & 1. 5020 & 1. 5018 \\
\hline Benzene ....... & 1. 5635 & 1.4796 & 1.5865 & 1. 5780 & 1. 6065 & 1.5885 \\
\hline $\begin{array}{l}\text { Carbon tetra- } \\
\text { chloride }\end{array}$ & 1. 5552 & 1.5630 & & & 1. 6070 & \\
\hline Ethanol. & & & & & 1. 0 & \\
\hline
\end{tabular}

Table 3. Analysis of six oils

\begin{tabular}{|c|c|c|c|c|c|c|c|c|c|c|}
\hline & \multirow{2}{*}{ Oil samples } & \multicolumn{5}{|c|}{ Chromatographic separation [13], eluants } & \multicolumn{4}{|c|}{ Sulfuric-acid extraction [24] } \\
\hline & & $\begin{array}{l}\text { First por- } \\
\text { tion of } \\
\text { pentane }\end{array}$ & $\begin{array}{l}\text { Second por- } \\
\text { tion of } \\
\text { pentane }\end{array}$ & Benzene & $\begin{array}{l}\text { Carbon } \\
\text { tetrachlo- } \\
\text { ride }\end{array}$ & Ethanol & Paraffins & $\begin{array}{l}\text { Second } \\
\text { acidaffins }\end{array}$ & $\begin{array}{c}\text { First } \\
\text { acidaffins }\end{array}$ & $\begin{array}{c}\text { Nitrogen } \\
\text { bases }\end{array}$ \\
\hline $\begin{array}{l}\text { I } \\
\text { II } \\
\text { III } \\
\text { IV } \\
\text { V } \\
\text { VI }\end{array}$ & $\begin{array}{l}\text { Circosol } 2 \times \mathrm{H} \\
\text { Sundex } 53 \\
\text { SPX97 } \\
\text { Philrich } 5 \\
\text { Dutrex } 20 \\
\text { Califlux TT }\end{array}$ & $\begin{array}{r}\% \\
53.4 \\
25.13 \\
25.97 \\
11.04 \\
5.98 \\
10.66\end{array}$ & $\begin{array}{l}\% \\
2.0 \\
1.68 \\
4.84 \\
6.15 \\
1.24 \\
0.81\end{array}$ & $\begin{array}{l}\% \\
41.3 \\
67.98 \\
64.25 \\
75.67 \\
80.58 \\
75.18\end{array}$ & $\begin{array}{r}\% \\
0.7 \\
.94 \\
.79 \\
.25 \\
.78 \\
1.08\end{array}$ & $\begin{array}{r}\% \\
2.6 \\
5.98 \\
5.00 \\
6.33 \\
10.57 \\
12.12\end{array}$ & $\begin{array}{r}\% \\
50.1 \\
23.8 \\
24.5 \\
9.6 \\
6.1 \\
10.5\end{array}$ & $\begin{array}{l}\% \\
41.5 \\
54.9 \\
53.3 \\
61.2 \\
46.5 \\
47.2\end{array}$ & $\begin{array}{r}\% \\
6.2 \\
14.8 \\
14.5 \\
16.8 \\
23.5 \\
20.9\end{array}$ & $\begin{array}{r}\% \\
2.2 \\
6.5 \\
7.7 \\
12.4 \\
23.9 \\
21.4\end{array}$ \\
\hline
\end{tabular}




\section{Experimental Procedure}

The infrared spectra were obtained with a PerkinElmer 21 double-beam spectrophotometer equipped with a sodium chloride prism for the range between 2 and $15 \mu$ and with a cesium bromide prism for the range between 15 and $40 \mu$. A cell holder was used, which was heated to $50^{\circ}$ or $60^{\circ} \mathrm{C}$ for the more viscous materials, such as the nitrogen-base fractions. It was shown that the spectrum of the heated materials was the same as that of the same material cooled in the cell to room temperature. The cells were assembled in the holder with a two-piece lead spacer open at the top and bottom. The sample was drawn downward between the windows by a suction tube applied to the bottom of the assembly. In this way it was possible to hold the percentage transmittance for successive loadings constant to within 0.5 percent. Solid samples were incorporated in $\mathrm{KBr}$ disks [31, 33], $9.5 \mathrm{~mm}$ in diameter and about $1 / 2 \mathrm{~mm}$ thick.

The ultraviolet spectra were obtained with a Cary 12 double-beam spectrophotometer, using as solvent methylcyclohexane, which had been purified by fractionating it through a column of silica gel. Only those cuts having the spectrum characteristic of the pure material were used. Twenty-millimater cells were used throughout.

\section{General Discussion}

It would not be expected, of course, that a spectroscopic study would completely elucidate the extremely complex composition of the oils themselves. However, the fractionations separated the molecules present into groups having similar characteristics. Consequently, the number and types of compounds in the fractions are not only greatly reduced, but the nature of the separation itself serves, to some extent, as a guide to indicate the type of compounds that may be present, thus supplementing the interpretation of the spectra.

Even following chemical fractionation, it would not be expected that spectroscopic studies would elucidate individual molecular species in these fractions, which are themselves mixtures of many compounds of either similar polarity or similar affinity for sulfuric acid. However, spectroscopic studies, especially infrared spectroscopy, can elucidate certain structural configurations and functional groups. If the optical absorption, due to a given structure, is virtually independent of the rest of the molecule, as are most structures absorbing in the region between 2 and $7.5 \mu$, and many molecules in the mixture contain such a structure, then the absorptions will reinforce each other, and a well-defined absorption band will be found. An example of such an absorption band is that due to the aliphatic $\mathrm{C}-\mathrm{H}$ stretching vibration at $3.4 \mu$. However, if an absorption can occur anywhere in a wide wavelength region, depending on the structures adjacent to the group, as is often the case in the region beyond $7.5 \mu$, then the resulting absorption by the mixture will, at best, be seen as a broad, poorly defined "swelling" in the general background. In many cases, the meaning of the absorption will be understood only by comparing several curves made from mixtures containing varying quantities of structures of this type, along with other more readily identified structures related to them in some fashion. It is here that a knowledge of the probable chemical nature of the fraction in question and correlation of the absorption phenomena with known physical and chemical properties becomes important. An example of this type of absorption is the skeletal stretching vibration of aliphatic chains in the region between 8 and $11 \mu$.

Because it facilitates understanding and interpretation of the spectra, we will consider the fractions in the order in which they are eluted successively from the chromatographic column, and relate, where possible, similar fractions obtained by acid extraction. In most cases, only one curve will be presented as representative of those obtained for the particular fraction under discussion. Variation of the other similar fractions from the one presented will be discussed in the text.

In the following discussion, reference has of ten been made to the recent book by Bellamy [2], which contains assignment charts and a detailed discussion of the relation between structural groups and absorption bands, with appropriate references to the original literature. Similar use has been made of the book by Randall, Fowler, Fuson, and Dangl [23] and of the article by Colthup [7], which also contain assignment charts and appropriate discussion.

\section{Infrared Spectra-2- to 15-Micron Region}

Figures 1, 3, 4, 5, 6, and 7 give the spectra in the region from 2 to $15 \mu$ for samples obtained by acid extraction and chromatographic separation. The spectra displaced to the lower part of figures 1,4 , and 5 , were obtained from samples of the first pentanebenzene-, and carbon tetrachloride-eluted portions, respectively, of the six oils separated chromatographically. The curves in the upper portion of these figures are for typical fractions of the four distillates separated by acid extraction. Figures 3 and 6 show examples of spectra of the second pentane- and ethanol-eluted portions, respectively.

\section{Paraffins and First Pentane-Eluted Fractions}

The spectrum in the upper portion of figure 1 was obtained on the portion of an oil insoluble in 30percent fuming sulfuric acid (distillate 3, paraffin (a)). It is qualitatively similar to that obtained on the first pentane-eluted portion of oil $\mathrm{V}$ in the lower part of the same figure.

These two spectra show the usual absorption pattern of a typical mineral oil [19]. There is no evidence of $\mathrm{O}-\mathrm{H}, \mathrm{N}-\mathrm{H}, \mathrm{C}=\mathrm{C}$, etc., except that the spectrum of one of the oil fractions (oil IV) has a weak band at $6.22 \mu$, suggesting aromatic or conjugated unsaturation and one at $12.2 \mu$, which could be caused by out-of-plane bending of a carbon- 


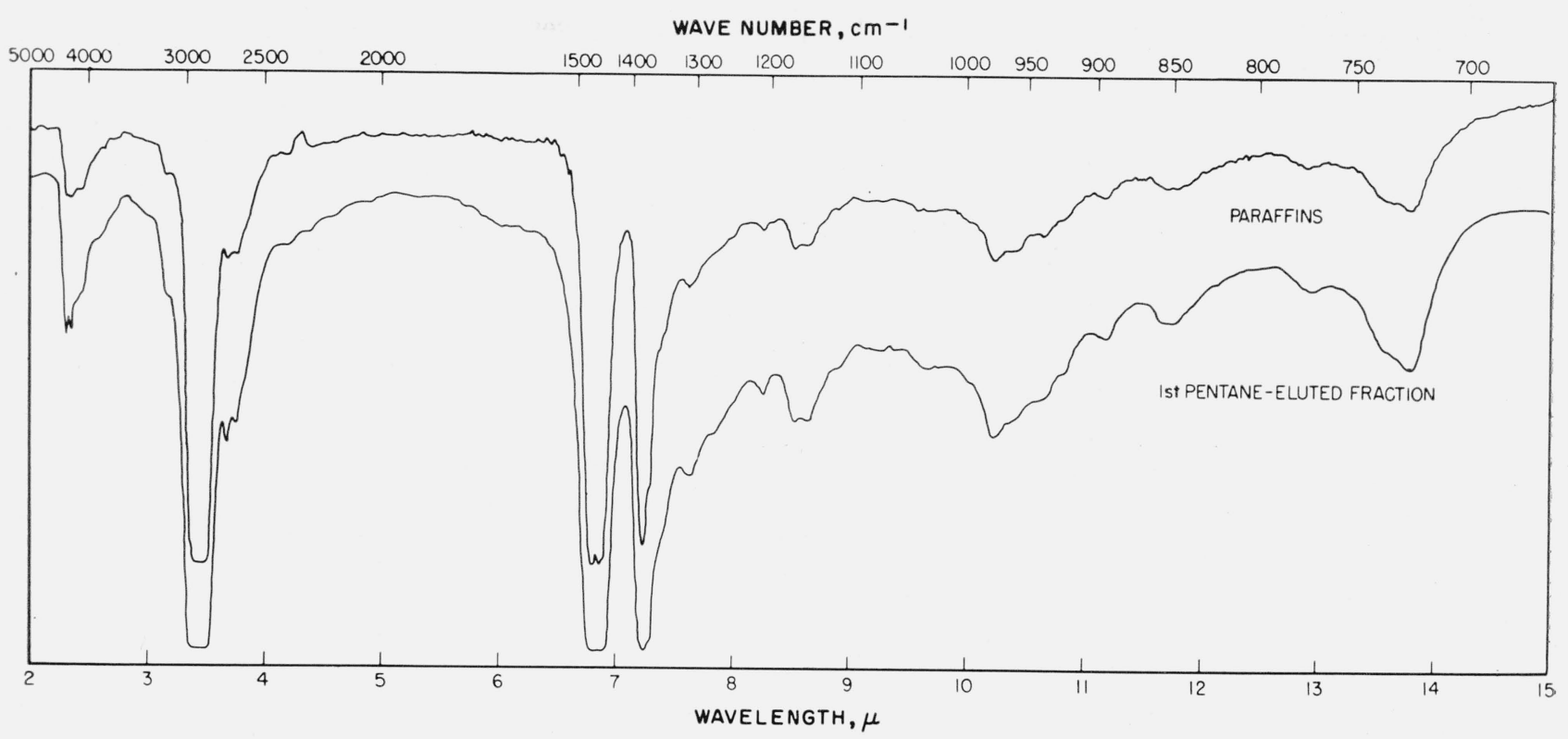

FIGURE 1. Infrared spectra of paraffins $(a)$ distillate 3, and first pentane-eluted fraction of oil $V$.

hydrogen bond on an aromatic ring. The absence of these groups is consistent with the chemistry of the methods of separation [13, 25, 27].

There is a strong absorption-band characteristic of $\mathrm{C}-\mathrm{H}$ stretching at 3.4 to $3.5 \mu$, one in the region of 6.8 to $6.9 \mu$ related to $\mathrm{CH}_{2}$ deformation and asymmetric $\mathrm{CH}_{3}$ deformation, and one at 7.2 to 7.3 related to symmetric $\mathrm{CH}_{3}$ deformations. The strong band at $13.8 \mu$ is characteristic of $\mathrm{CH}_{2}$ rocking vibrations. This band is not observed at this wavelength in aliphatic chains containing less than four successive $\mathrm{CH}_{2}$ groups, and it shifts to shorter wavelengths with a decrease in chain length. From the work of Hastings, Watson, Williams, and Anderson [15], it seems reasonable, in the absence of aromatic absorption at $6.2 \mu$ to assign the weak absorption at $13 \mu$ to $\mathrm{CH}_{2}$ groups in a chain 1 or 2 methylene units in length, the shoulder at $13.6 \mu$ to chains containing 3 methylene units, and the peak at 13.80 to $13.85 \mu$ to chains containing 4 or more methylene units. Even this latter absorption shifts slightly to longer wavelengths as its intensity increases.

A study of the American Petroleum Institute (API) series [1] of infrared curves of branched isomers of decane shows that increased branching produces a number of bands in the 8 - to $12-\mu$ region. In many cases these new bands seem to cluster about the 8 - to 9 - and 10 - to $11-\mu$ regions. The presence of saturated rings seems to produce a similar spectrum, but Bellamy [2] cites articles in which evidence is given to show that the absorption in the 8- to $9-\mu$ region tends to be due to branching and that in the 10 - to $11-\mu$ region to ring formation, in the absence of unsaturation and certain polar groups that also absorb in this region.

Figure 2 shows spectra in the 7.5 - to $15-\mu$ range for the first pentane-eluted portion of six oils from different parts of the country. There are three fairly good isosbestic points (wavelengths at which absorption is independent of the concentration of components) for these mixtures at 7.8, 12.4, and $14.8 \mu$, which divide the spectra into two parts. It will be noted that there is a negative correlation between the transmittance at 8.5 and $10.2 \mu$ and that due to the methylene rocking vibration at $13.8 \mu$. This is indicated by the inverted order of the arabic numbers. A decrease in $\mathrm{CH}_{2}$ groups implies, for this type of material, an increase in either branching or cyclization, and in the light of Bellamy's evidence, it is reasonable to assume that the absorption centered at $8.5 \mu$ is due to branching and the one at $10.2 \mu$ to ring formation. It is interesting to observe that there is a correlation between the absorbances of the bands at 8.5 and $10.2 \mu$ and the refractive index of the respective fractions. It has been shown, from a study of many compounds [30], that increased branching, except in the 2 position, or cyclization, tends to raise the index of refraction. However, in this case, variations in molecular weight among the fractions could cause a similar effect. The changes in transmittance for the three wavelengths and the corresponding values for refractive index are given in table 4. The first high value for refractive index was obtained on the fraction that showed signs of aromatic absorption at $6.22 \mu$.

Thus, these materials can be said to contain varying quantities of saturated rings and chains of different lengths, some of which are branched. It is consistent with chemical knowledge that materials of this type should be eluted from silica gel by a hydrocarbon such as pentane, and that they should be least reactive with 30 -percent fuming sulfuric acid. 


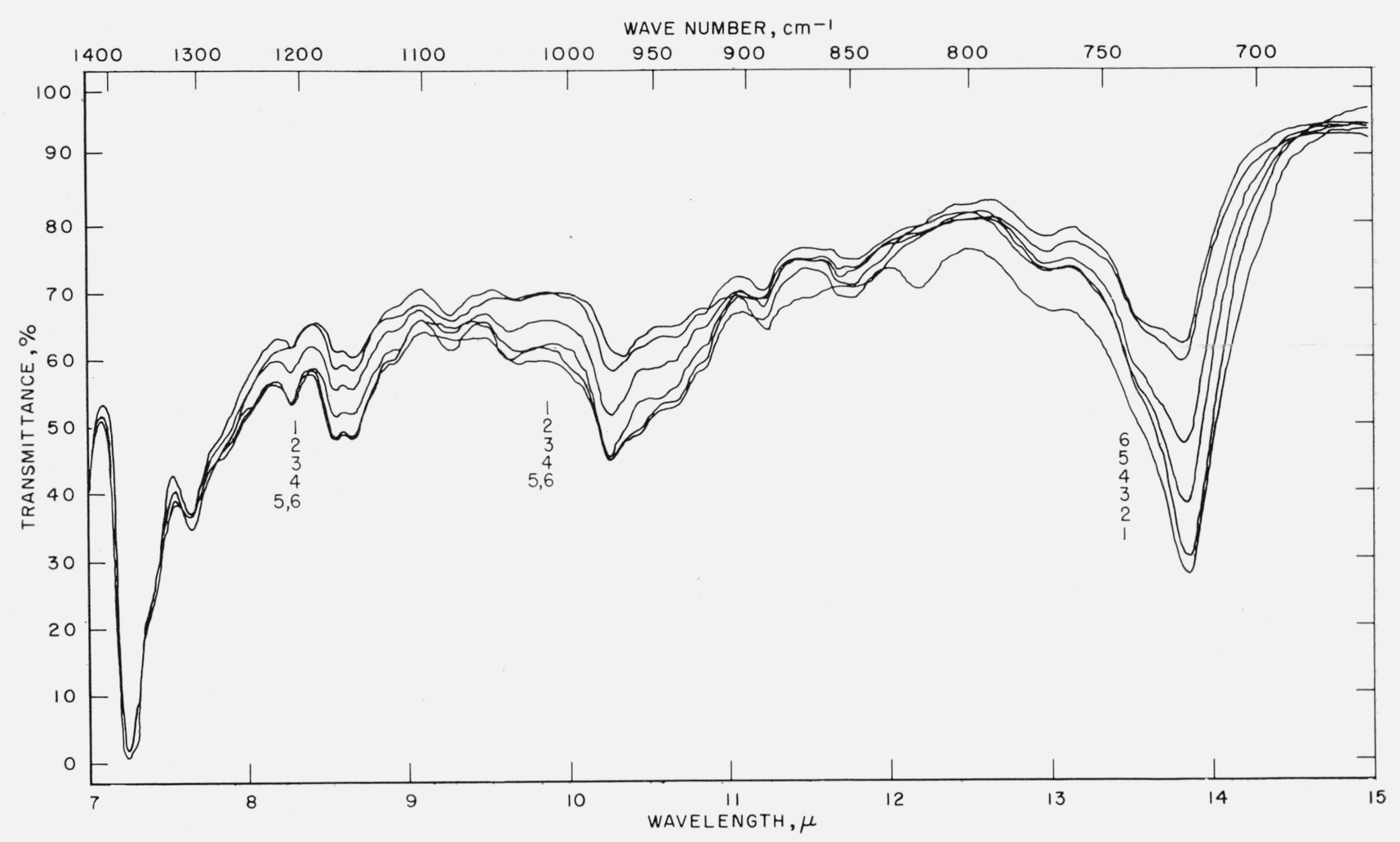

FIGURE 2. Infrared spectra of first pentane-eluted fractions from six different oils ( 7 to $15 \mu$ range).

See table 4 for identification of the oils.

TABLE 4. Index of refraction versus percentage transmittance First pentane-eluted fractions

\begin{tabular}{|c|c|c|c|c|c|}
\hline & \multirow{2}{*}{ Number of oil a } & \multicolumn{3}{|c|}{ Transmittance (micron) } & \multirow{2}{*}{$n_{D}^{25}$} \\
\hline & & 13.8 & 10.2 & 8.5 & \\
\hline $\begin{array}{l}\text { IV } \\
\text { III } \\
\text { II } \\
\text { I } \\
\text { V } \\
\text { VI }\end{array}$ & $\begin{array}{l}(1) \\
(2) \\
(3) \\
(4) \\
(5) \\
(6)\end{array}$ & $\begin{array}{c}\% \\
27.9 \\
30.3 \\
38.3 \\
47.2 \\
59.6 \\
61.9\end{array}$ & $\begin{array}{c}\% \\
60.3 \\
58.3 \\
51.7 \\
45.2 \\
44.9 \\
44.9\end{array}$ & $\begin{array}{c}\% \\
61.2 \\
58.7 \\
55.6 \\
51.6 \\
48.1 \\
48.1\end{array}$ & $\begin{array}{l}\text { 1. } 4845 \\
\text { 1. } 4800 \\
\text { 1. } 4805 \\
\text { 1. } 4882 \\
\text { 1. } 4915 \\
\text { 1. } 4925\end{array}$ \\
\hline
\end{tabular}

a The numbers in parentheses are the designations given in figure 2 .

\section{Second Pentane-Eluted Fractions}

The spectrum in figure 3 was obtained on the material eluted from oil II by the second half of the pentane put through the column. This spectrum has a number of bands not present in the spectrum of the first portion eluted with pentane; these bands, in turn, are different from those in the spectrum of the benzene-eluted portion in the lower part of figure 4

First, there is a strong band at $6.2 \mu$, with some indication of doubling (shoulder at about 6.26) and another shoulder at $6.7 \mu$, all of which are probably due to aromatic ring $\mathrm{C}=\mathrm{C}$ stretching vibrations, although the band at $6.2 \mu$ might also indicate nonaromatic conjugated double bonds. As shown by Young, DuVall, and Wright [43], the pattern of bands between 5 and $6 \mu$ is characteristic of aromatic compounds. The pattern of bands beyond $11 \mu$ (about 11.37, 11.7, 12.2, 12.84, 13.3 to 13.5, 13.8, and $14.3 \mu$ ) cannot, of course, in themselves, give positive identification of structural groups. However, it is consistent with Colthup's chart [7], and with Bellamy [2], to correlate these absorptions with mono-, di-, tri-, tetra-, and penta-substituted aromatic compounds and with $\alpha^{-}$and $\beta$-substituted napthalenes.

The above absorptions are due to $\mathrm{C}-\mathrm{H}$ perpendicular bending modes, typical of these types of substitution. Again, the band at $13.8 \mu$ is probably very largely due to the methylene rocking absorption from the substituted side chains. Plots of intensities of the other bands beyond $11 \mu$ for different oils show a rough correlation with the intensity of the band at $6.2 \mu$. This is in agreement with the assignment of these bands to absorption from aromatic molecules. No more than a rough correlation is to be expected, because variations among the several types of aromatic compounds from oil to oil would be anticipated. This type of variation is emphasized by the fact that one of the fractions was markedly different from the others with respect to the relative intensities of the bands beyond $11 \mu$. 


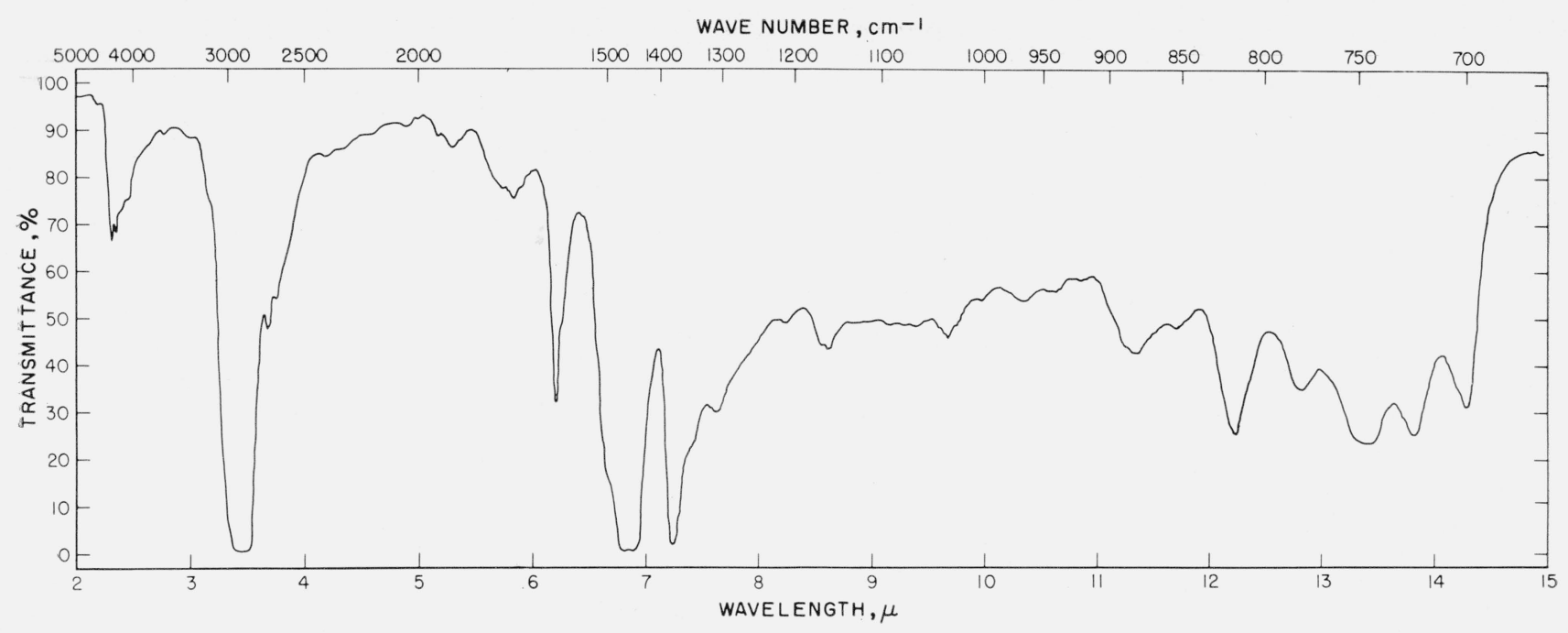

FIGURE 3. Infrared spectrum of second pentane-eluted fraction of oil II.

The intensity of the band at $8.54 \mu$, attributed to branching, may be somewhat reduced in comparison to that in the first pentane-eluted portions. The intensities of this band in this fraction of the different oils are inversely related to the intensities of the band near $13.8 \mu$. The position of the band near $13.8 \mu$ shifts acain to longer wavelengths with increasing intensity just as in the case of the first pentane-eluted portions. The band at $10.2 \mu$ attributed to alicyclic compounds appears to be greatly reduced, if not eliminated, when compared to the first pentane-eluted portion. However, aromatic compounds also produce weak to medium bands in the region from 8.5 to $10 \mu$. Indeed, the absorption at $9.6 \mu$ is probably due to the aromatic compounds discussed previously. It is possible, therefore, that aromatic absorptions below $10 \mu$ and above $11 \mu$ may increase the general background, making the reduction in the absorption at $10.2 \mu$ more apparent than real.

Some of the absorption at $5.84 \mu$ might be due to compounds containing carbonyl groups. The absorption characteristics in this region seem to vary from oil to oil, with some fractions having an absorption at $5.74 \mu$, suggesting the presence of two types of carbonyls. There is only very slight evidence of $\mathrm{OH}$ or $\mathrm{NH}$ in one of the oils.

The spectrum of one of the oils (oil VI) was different from that given in figure 3 , in that it showed strong aromatic absorptions near 11.4 and 12.2, and no band at $9.6 \mu$.

Thus, these materials are probably hydrocarbons containing mono-, di-, and tri-substituted aromatic rings, with perhaps some naphthenic rings. The aliphatic side chains may be branched and could connect one ring to another. However, unpublished work of Termini and Glasgow [13], based on absorption studies, has shown that these compounds probably contain no more than a single aromatic nucleus. It is reasonable to assume that materials of this type would adhere more strongly to the silica gel than do simple aliphatic, branched, and cyclic hydrocarbons.

\section{First and Second Acidaffins and Benzene- Eluted Fractions}

The two spectra in the upper portion of figure 4 were obtained respectively from two portions of an oil (distillate 3 ); one portion does not react with 85percent sulfuric acid, but is removed by 98-percent sulfuric acid (1st acidaffins); and the other portion does not react with 98-percent sulfuric acid, but is removed with 30-percent fuming sulfuric acid $(2 \mathrm{~d}$ acidaffins). These spectra are remarkably similar to that of the benzene-eluted portion of oil $\mathrm{V}$ in the lower part of figure 4.

It will be noted that over the whole spectrum the first acidaffins are more optically dense than the second acidaffins. This is generally true for all the acidaffin portions of the three distillates examined. The reasons for an increase in over-all optical density are not too well understood. An inspection of table 1, however, shows that the indices of refraction, densities, and carbon-to-hydrogen ratios are greater for the first acidaffins, whereas the molecular weights of the second acaidffins are greater, with one exception. It is reasonable to assume that the more chemically active materials in the first acidaffins would be more subject to carbonization than the second acidaffins. Such effects would tend to raise the density, carbon-to-hydrogen ratio, and optical density of the first acidaffins. Furthermore, the optical density over the whole spectrum is less for the benzene-eluted fraction, which is not subject to this treatment, than for any of the acidaffins. It should be noted that the transmittance ordinate has been omitted from figure 4 because the benzeneeluted fraction has been displaced below the other two curves.

The spectra of the three types of fractions show, in addition to the aromatic bands between 5 and $6 \mu$ and those at 6.2 and $6.7 \mu$ present in figure 3 , shoulders at $3.3 \mu$, which are expected from the $\mathrm{C}-\mathrm{H}$ 


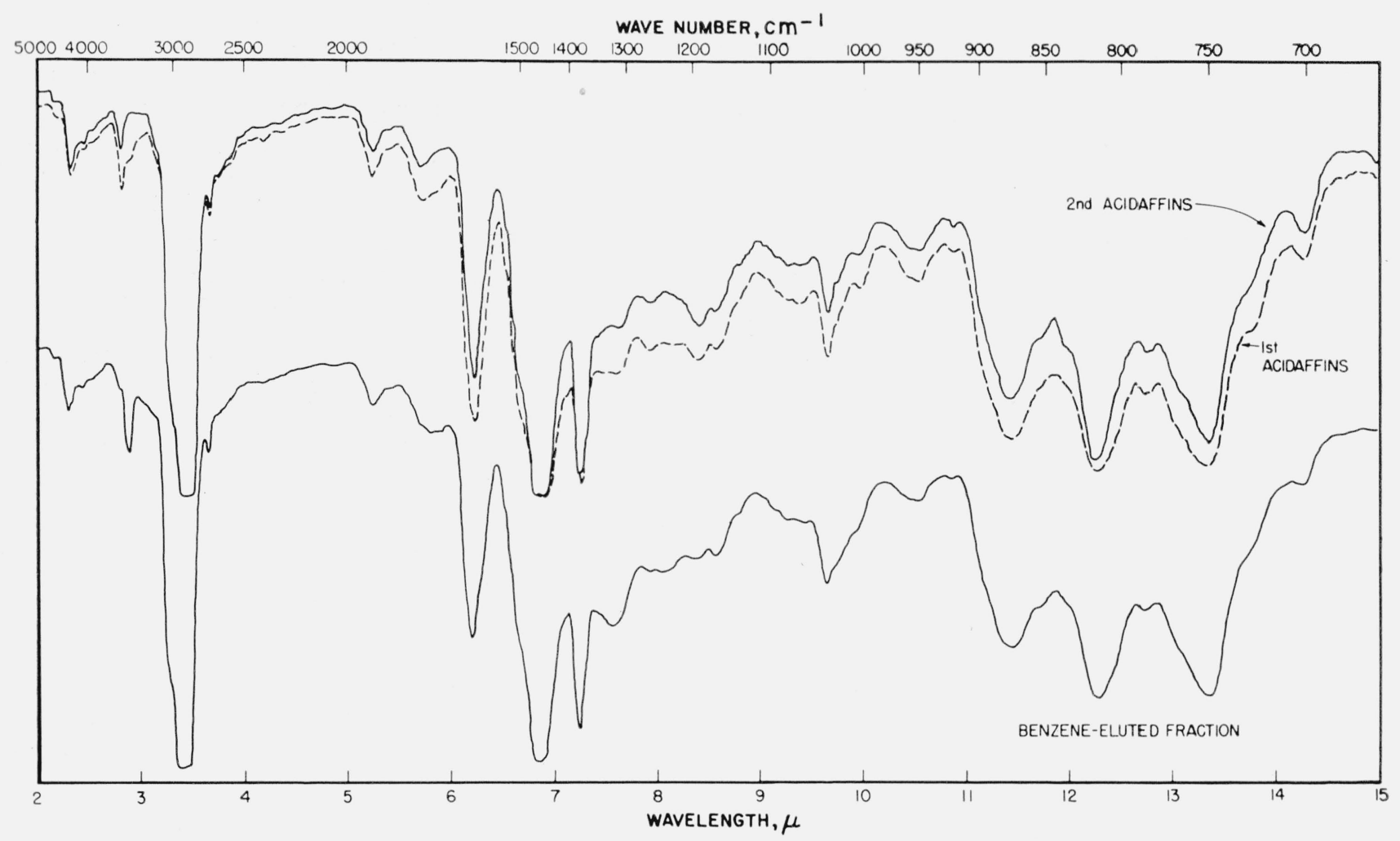

FIGURE 4. Infrared spectra of first and second acidaffins of distillate 3 and benzene-eluted fraction of oil $V$.

vibrations of aromatic molecules. Furthermore, the aromatic absorptions at $11.4,12.2$, and $13.4 \mu$ are greatly increased, with the other absorptions observed in figure 3 at $11.7,12.8,13.1$, and $14.3 \mu$ fading into the background. This could result from the following effects: (1) A change in the distribution of the substituted aromaties, and (2) the presence of polynuclear aromatic compounds.

Benzanthracene and dibenzanthracene, as well as their derivatives, can be shown from the curves of Cannon and Sutherland [5] to have absorption bands of this type. The spectrum of diphenyl benzidene [17], with the $\mathrm{N}-\mathrm{H}$ bands deleted and aliphatic $\mathrm{C}-\mathrm{H}$ bands added, strongly resembles that of the spectra in figure 4. Finally, other polynuclear aromatic compounds have bands occurring at one or another of these positions $[5,8]$, so that the envelope produced by a mixture of them would be expected to have the contour found here. This pattern of bands near 11.4 12.2 , and $13.4 \mu$ has been observed in the spectra of other natural products. Friedel and Pelipetz [11] and Friedel and Queiser [12] reported them in the spectra of coal fractions. Cannon [4] has reported them in the spectra of powdered coal, and Stewart [32] has observed them in fractions of petroleum asphalts. Furthermore, in their mass-spectrometer studies of high-molecular-weight hydrocarbons, O'Neal and his coworkers [20] have found polynuclear aromatics in lubricating-oil extracts, which generally contain substantial amounts of resins.

A strong correlation is once more found between the variation in the intensities of the bands at 11.4,
12.2 , and $13.4 \mu$ among the chromatographic fractions and the intensity of the aromatic band at $6.2 \mu$.

It is well known that an increase in aromaticity tends to increase the index of refraction. It is, therefore, interesting to note that a plot of $n_{D}$ versus $I / I_{0}$ for the $6.2-\mu$ band of these fractions yields a fairly straight line of negative slope. As before, this effect could also be due to variations in molecular weight. The increase in the band at $9.65 \mu$ over that noted in figure 3 is consistent with either a change in the distribution of substituted aromatics or the presence of smaller fused-ring systems. An examination of Cannon and Sutherland's curves [5] shows that the intensities of the bands near $9.6 \mu$ are relatively lower for the larger fused systems. Either possibility is consistent with the increased index of refraction.

Furthermore, the above effects are also consistent with the observed reduction in the intensity of the band at $13.8 \mu$ due to the methylene rocking mode that depends on the presence of at least four consecutive $\mathrm{CH}_{2}$ groups. The bands near $8.5 \mu$ attributed to chain branching are still present and especially noticeable in the acidaffin fraction. However, the band at $10.2 \mu$ assigned to saturated rings appears to have disappeared at least in the form present in figure 1 . The band of $10.5 \mu$, not present in previous fractions, could result from the fused aromatic rings. The outof-plane motion of the hydrogens in the trans doublebond configuration also causes absorptions in this region. 
There is a possibility that some carbonyl groups are present in these fractions, contributing to the absorption near 5.75 and $5.84 \mu$. Again, conjugated nonaromatic $\mathrm{C}=\mathrm{C}$ bonds might contribute to the absorption at $6.2 \mu$. Weak, but sharp, bands at $2.88 \mu$ might arise from $\mathrm{OH}$ or $\mathrm{NH}$ groups. There is a general increase in absorption in the region near $8 \mu$, where Friedel and Pelipetz [11] observed aromatic ether bands in their coal fractions. This absorption has the effect of obscuring the 8.5- $\mu$ chain-branching band, particularly in the benzene-eluted portion.

Thus, the first and second acidaffins and the benzene-eluted portion of the oils appear to be largely hydrocarbons with more marked aromatic character than those in the second pentane-eluted portion, but still containing some side chains of more than four carbon atoms in length. These side chains may also be branched. These fractions may be mixtures of substituted aromatic rings joined with methylene groups as well as polynuclear aromatic hydrocarbons. In the chromatographic fractions, the degree of aromaticity and the concentration of $\mathrm{OH}$ and $\mathrm{NH}$ groups vary from one oil to another. There is also some variation of these polar groups from one distillate to another of the acidaffin fractions.

In considering the foregoing discussion of the first and second acidaffins, and the following discussion of the two nitrogen-base fractions, it should be remembered that these fractions are actually mixtures and are, therefore, only concentrates of the designated component (see the group analysis of these samples in table II of Rostler and White [29]).

\section{Nitrogen Bases, Groups I and II and Carbon Tetrachloride-Eluted Fractions}

The two spectra in the upper portion of figure 5 were obtained on the nitrogen bases, groups I and II from distillate 3 , as indicated. Nitrogen bases, group I, are removed from a petroleum ether solution of the oil with dry $\mathrm{HCl}$ gas. Nitrogen bases, group II, are removed from the remaining solution with 85-percent sulfuric acid. Groups I and II may be removed together with 85-percent sulfuric acid. These spectra are remarkably similar to the spectrum in the lower portion of figure 5, which was obtained on the material of oil IV eluted from the column with carbon tetrachloride.

It will be noted that the optical density of the nitrogen bases, group $I$, is greater in the region between 11 and $13.5 \mu$, whereas it is less in the region between 7.5 and $11 \mu$. Furthermore, the carbon-tohydrogen ratio is larger for the nitrogen bases, group I, than for the nitrogen bases, group II. These facts may be interpreted to indicate that the compounds in the nitrogen bases, group I, are more highly aromatic than those in group II. It will be noted that the spectra of these fractions show some loss of detail as compared with those in figure 4, as well as other evidences of a difference in aromatic character.

Both nitrogen-base fractions have fairly strong absorptions near $3.1 \mu$, probably due to $\mathrm{N}-\mathrm{H}$ stretching, and bands in the region between 5.9 and $6.0 \mu$, probably due to amide carbonyls, although unsaturated aldehydes and ketones can also absorb in this region. However, there is no evidence of the bands characteristic of aldehydes in the 3.4 - to 3.7- $\mu$ region. The carbonyl absorption is much stronger in the nitrogen bases, group II, suggesting that nitrogen in this group is predominantly amide in nature, whereas that in the nitrogen bases, group I, is largely present in the form of amines. This appears to be consistent with the elemental analysis of the three sets of fractions given in table 1 . In each case the amount by which the sum of the elements fails to equal 100 percent is greater for the nitrogen bases, group II, suggesting a higher oxygen content. It can be noted that the absorptions of both $\mathrm{N}-\mathrm{H}$ and $\mathrm{C}=\mathrm{O}$ stretching vibrations occur at slightly longer wavelengths in the nitrogen bases, group I; this possibly indicates that hydrogen bonding is more pronounced in this fraction. It might be expected that susceptibility to hydrogen bonding would be related to reactivity toward dry $\mathrm{HCl}$. Absorptions due to $\mathrm{N}-\mathrm{H}$ deformation in unsubstituted amides and primary amines contribute to the band at $6.25 \mu$. Weak bands at $6.5 \mu$ found in some of the spectra of both nitrogen bases and in a number of the spectra of the carbon tetrachloride-eluted fractions are probably due to the $\mathrm{N}-\mathrm{H}$ deformation of monosubstituted amides and secondary amines, but could also result from nitro compounds. A weak band appears at $5.2 \mu$ for the nitrogen bases and $5.3 \mu$ for the carbon tetrachloride-eluted fractions. This is in the region where amine hydrochlorides absorb. There is still evidence of straight chains of four or more methylene groups, none of cyclization, and little of branching. However, the general absorption near $8.0 \mu$ attributed to aromatic ethers in the spectra in figure 4 has increased in all fractions in figure 5 . The spectrum of the carbon tetrachloride-eluted portion appears most similar to that of the nitrogen bases, group II, with regard to the position of the bands for the polar groups. It should be noted that in all the spectra the absorption near $3.0 \mu$ could result in part from $\mathrm{OH}$ stretchings.

The aromatic absorptions between 11 and $15 \mu$ in the carbon tetrachloride-eluted portions differed widely from one oil to another. There were also differences in the polar absorptions near 3.0 and $6.0 \mu$. In fact, even the type of spectrum. given in figure 5 was obtained for only 4 of the 6 oils studied (oils I, III, IV, and VI), the spectra of the other 2 oils being different. Oil II had sharp bands at 7.9 and $8.9 \mu$, a widely different aromatic character with absorption bands at $11.8,12.6,13.7$, and $14.3 \mu$, quite different polar absorptions near 3.0 and 6.0 $\mu$, and a much reduced $\mathrm{CH}$ stretching absorption. Oil V had a rather high over-all absorption, with broad slight absorptions at 3.0, 3.4, 5.9, 6.2, 6.9, and $7.2 \mu$ and slight swellings at $11.7,12.4$, and 13.5 $\mu$. Even the nitrogen bases, groups I and II, from the different distillates of the same crude oil showed a variability in polar and aromatic constituents 


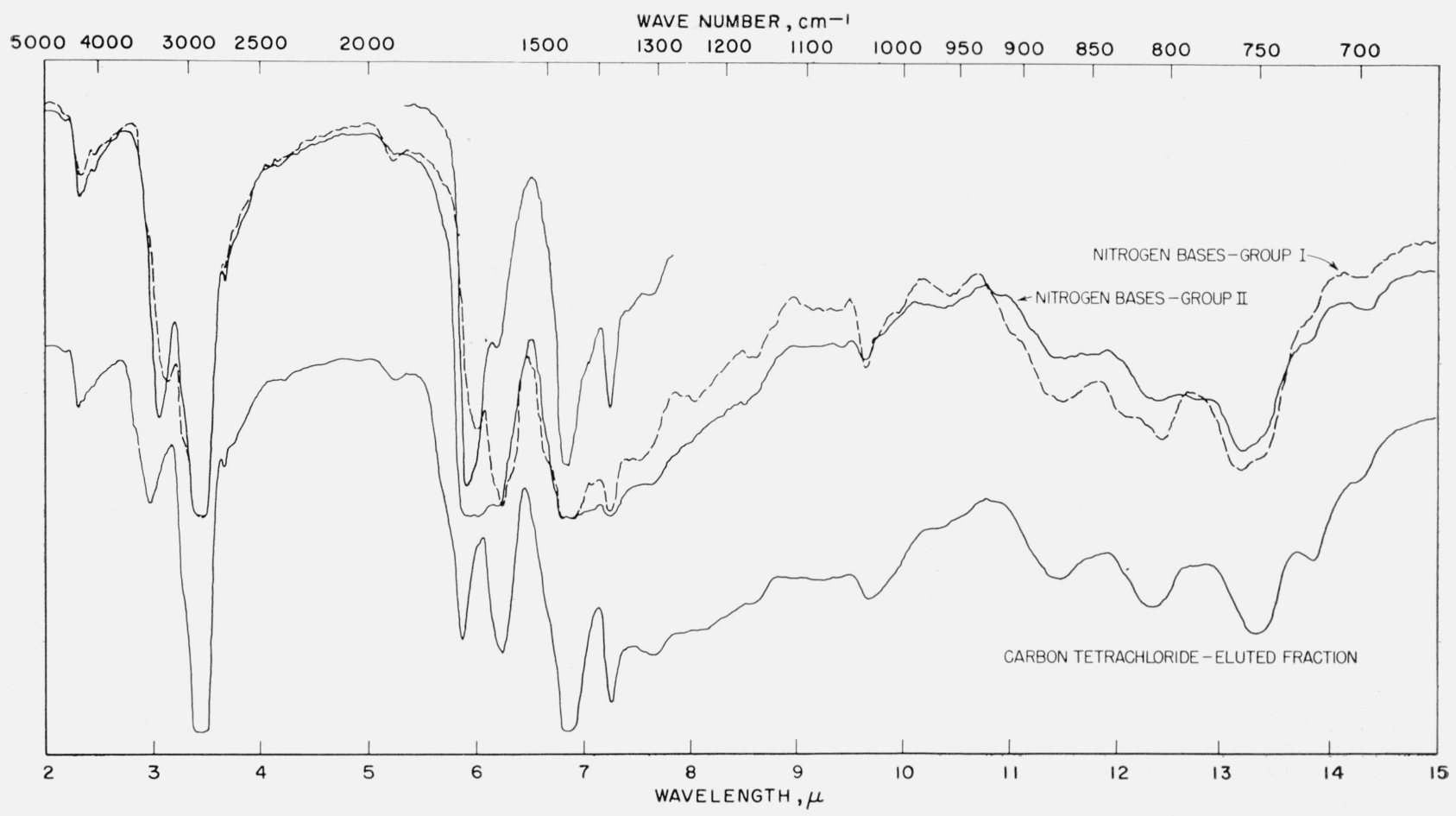

FIGURE 5. Infrared spectra of nitrogen bases, groups I and II, of distillate 3 and carbon tetrachloride-eluted fraction of oil IV.

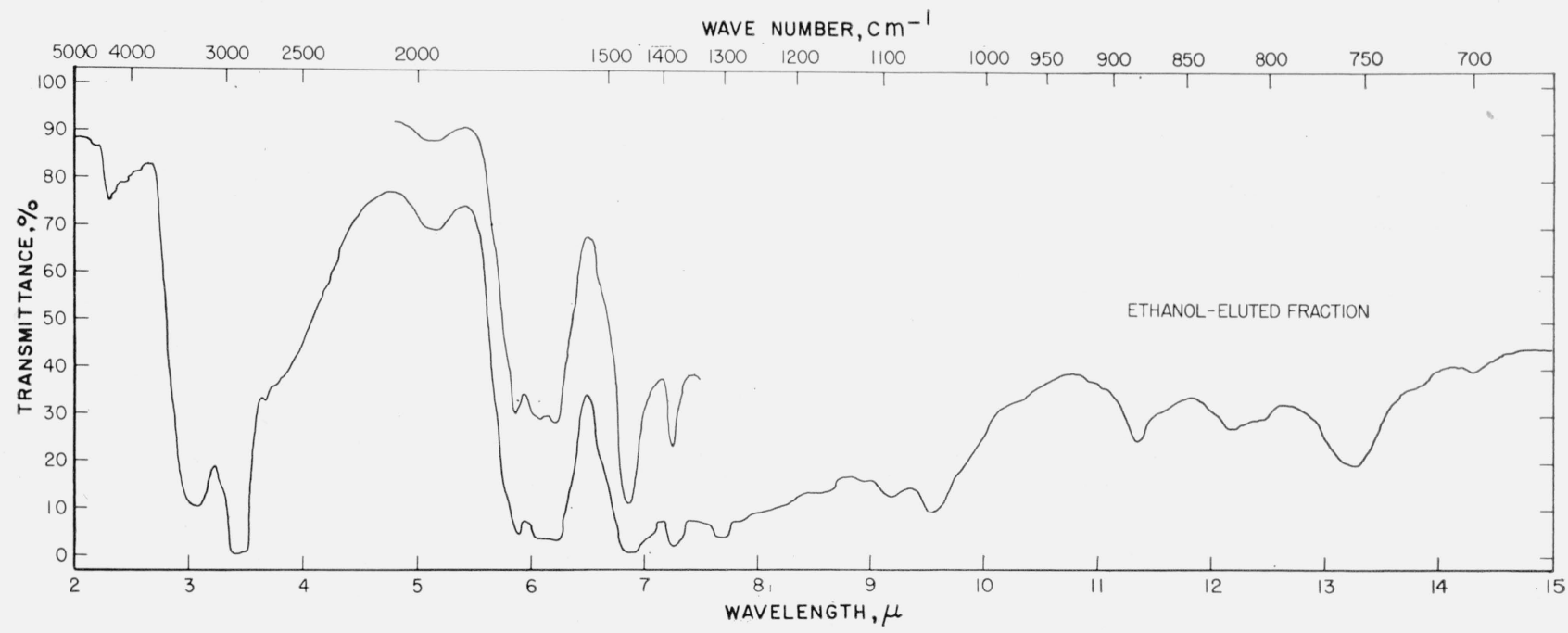

Figure 6. Infrared spectra of ethanol-eluted fraction of oil III.

from distillate to distillate. In the spectrum. of one of the nitrogen bases, a strong band appeared at $8.6 \mu$ (nitrogen bases, group II of distillate IV). The observed variability, in all cases, is much greater than that found in any of the fractions discussed previously. It is consistent with the chemistry of the separation to find a variety of amines in the nitrogen bases, group I, and a large variety of polar compounds containing $\mathrm{N}-\mathrm{H}, \mathrm{O}-\mathrm{H}$, and carbonyl groups in the nitrogen bases, group II.

\section{Ethanol-Eluted Fractions}

The spectrum in figure 6 obtained on the portion of oil III eluted with ethanol is similar to those in figure 5, except for the marked broadening of the absorption region on the long wavelength side of the $\mathrm{C}-\mathrm{H}$ stretching band at $3.4 \mu$. This is apparently due to the breadth of the band at $3.0 \mu$, which appears to extend "through" the $\mathrm{C}-\mathrm{H}$ band to beyond $4 \mu$. This conformation is characteristic of hydrogen 
bonding, as found, for example, in carboxylic acids. The band near $3.0 \mu$ varies considerably in wavelength and intensity from one oil to another. The aromatic character (bands beyond $11 \mu$ ) is again different from that found in the acidaffins, and there is variation from one oil to another. There are very strong bands in the range 5.64 to $6.08 \mu$. These are resolved in the spectrum of a thin film, as shown in the upper curve of figure 6 . The patterns of bands near $6.0 \mu$ for the six oils seem to fall into three categories. The two oils in category 1 (oils I and II) have common bands at 5.63 (weak), 5.8 (shoulder), 5.85 (strong), and $6.08 \mu$ (weak). Oil II has an additional weak band at $6.01 \mu$. Only these two oils have a strong peak at less than $3.0 \mu$. The three oils in category 2 (oils IV, V, and VI) have bands at 5.66 (shoulder), 5.82 (strong), and 6.02 to $6.04 \mu$ (strong). The single oil in category 3 (oil III) has bands at 5.87 and $6.08 \mu$. These bands probably represent a variety of carbonyl structures. There is evidence of saturated hydrocarbons from the strong bands at $3.4,6.8$, and $7.25 \mu$, but there is little evidence of branching, cyclization, or chains containing more than four $\mathrm{CH}_{2}$ groups. The general absorption near $8.0 \mu$ seems to have increased still further, and the band near $5.2 \mu$ has increased markedly in intensity.

These fractions contain compounds with aromatic nuclei, condensed or otherwise, and in addition to carboxylic acids, combinations of $\mathrm{OH}, \mathrm{NH}$, and $\mathrm{C}=\mathrm{O}$ in any form, including alcohols, phenols, amines, amides, aldehydes, and ketones. They also contain unconjugated $\mathrm{C}=\mathrm{C}(6.08-\mu$ band $)$, conjugated $\mathrm{C}=\mathrm{C}$, and aliphatic $\mathrm{CH}_{2}$ and $\mathrm{CH}_{3}$. The most marked characteristic of these fractions is the variation in composition, even of polar groups, from one oil to another, a variation that is probably greater than in the case of the carbon tetrachloride-eluted fraction. This variation may be expected because it is the most strongly polar group alone and not the remainder of the molecule, including other polar groups, which places a compound in this fraction. The variation in aromatic character of both the carbon tetrachloride- and ethanol-eluted fractions is to be expected because they are separated from the column on the basis of a polarity greater than their aromatic character alone.

\section{Asphaltenes}

The asphaltenes, figure 7 , show their aromatic character by the absorptions at $6.2,11.4,12.2$, and $13.4 \mu$. These bands are especially noticeable in the spectrum obtained with the $\mathrm{KBr}$ pellet containing the greater concentration of asphaltenes (lower curve). The presence of $\mathrm{CH}_{2}$ and $\mathrm{CH}_{3}$ groups is evident from the absorptions at $3.4,6.8$ to 6.9 , and $7.25 \mu$. The asphaltenes used here were obtained by $n$-nentane precipitation from a crude oil that had been airblown (designation $(\mathrm{A}-\mathrm{O}$ ) of Rostler and White [29]). They exhibit a fairly strong absorption band at $5.9 \mu$ due to the presence of carbonyl groups. This band was not present in the spectrum of asphaltenes obtained from crude oil that had not been airblown or in the spectrum of Gilsonite. The airblown sample was shown to contain more oxygen than either of the other samples [29]. The band at $2.9 \mu$ is due to the presence of water in the potassium bromide of the pellet. The low transmittance at shorter wavelengths is the result of scatter by the asphaltene particles. It is well known that asphaltenes may result from condensation or oxidation of aromatic portions of the oil. Thus, they may consist of polyamides (from the polar compounds) or condensed aromatic rings or both.

One of the oils was also separated by Kleinschmidt into four fractions by means of his chromatographic procedure for petroleum asphalts employing fuller's earth as an adsorbent and a different series of eluents from those used here [16]. The infrared spectra of these fractions resembled those of the fractions studied here.

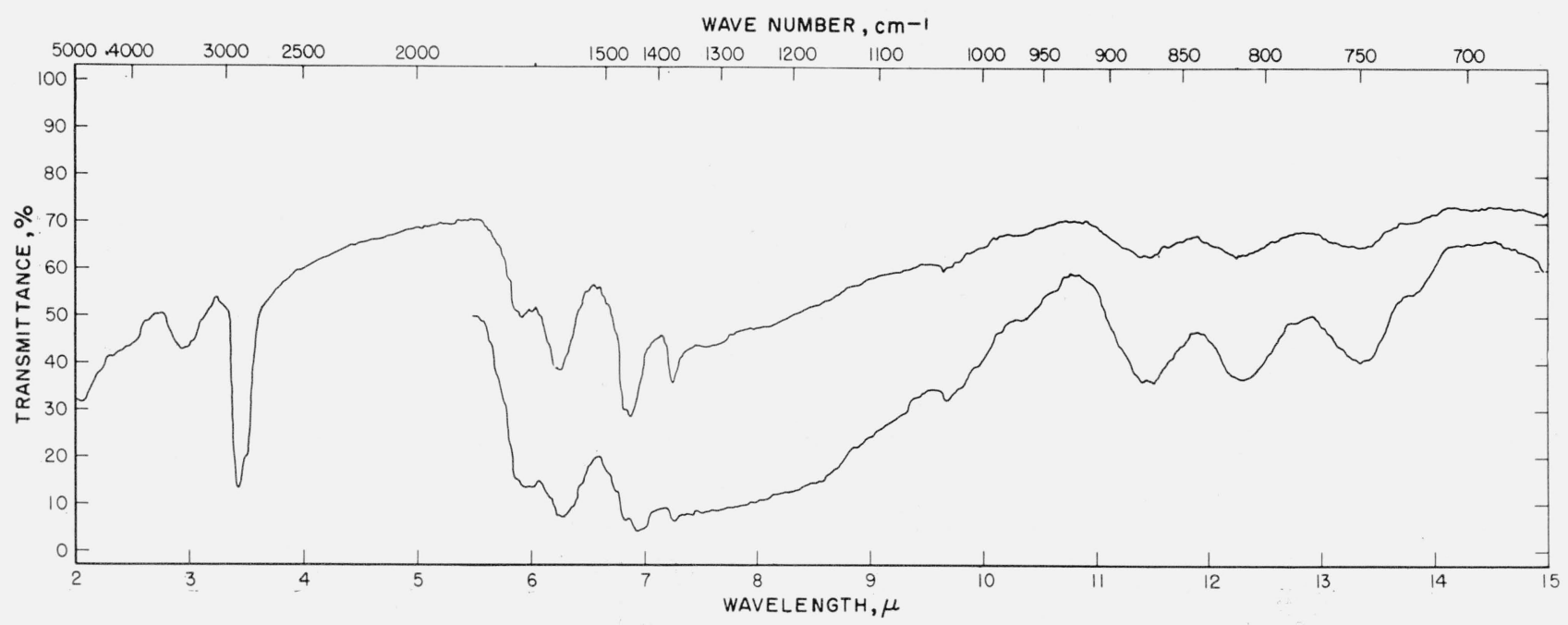

FIGURE 7. Infrared spectra of asphaltenes from air-blown crude oil (designation (A-O) of Rostler and White [29],) using the KBr pellet technique. 


\section{Far Infrared and Ultraviolet Spectra- Exploratory Studies}

Some exploratory work was done in the region between 15 and $40 \mu$, using typical benzene-, carbontetrachloride- and ethanol-eluted portions of oil IV. The curves in figure 8 indicate the type of spectra obtained in this region. The spectrum of the paraffins or the first pentane-eluted portion was not obtained; a typical mineral oil with no aromatic bands in the rock-salt region, shows no bands in this region. The absorption bands at 21 and $23.3 \mu$ in the benzeneand carbon-tetrachloride-eluted portions occur in a region where aromatic compounds absorb [7]. The spectrum of the ethanol-eluted portion retains the band at about $23 \mu$, but the $21-\mu$ band is missing. No other well-defined bands are found in these spectra, except for the weak bands at longer wavelengths, which are due to uncompensated atmospheric water vapor.

Ultraviolet spectra (fig. 9) were obtained on fractions of oil II eluted from silica gel with pentane, benzene, and methanol, using an earlier chromatographic procedure. These fractions had infrared spectra similar to those of the corresponding fractions presented earlier, with the exception that the methanol-eluted fraction had more pronounced aromatic bands at $11.4,12.2$, and $13.4 \mu$, and less pronounced bands arising from polar groups than did the ethanol-eluted fraction. Spectra of a number of fractions obtained by acid extraction are included in figure 10 .

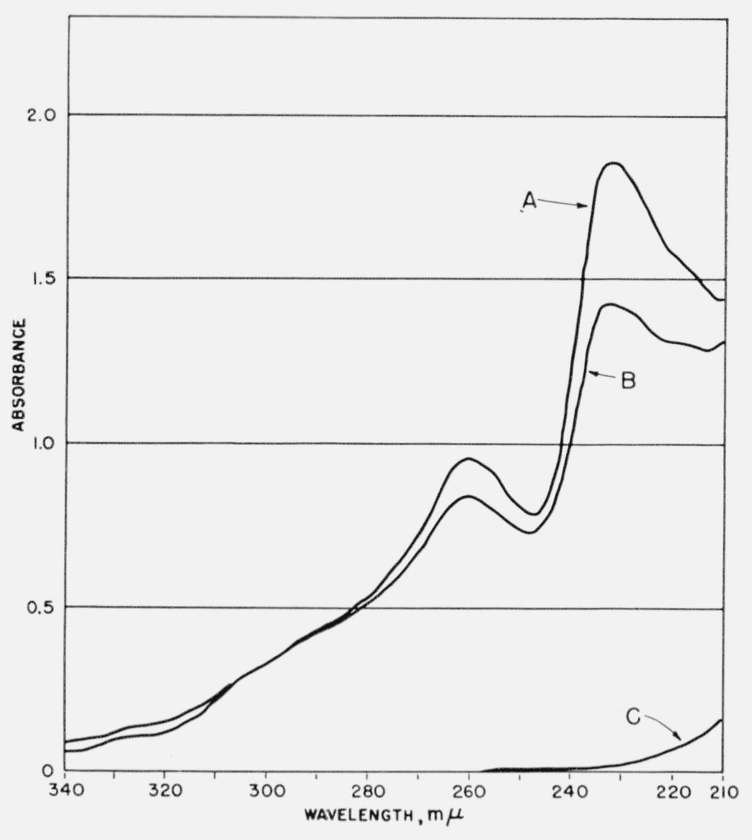

FIGURE 9. Ultraviolet spectra of fractions obtained by chromatographic separation of oil $I I$.

A, Benzene-eluted fraction (concentration $10.60 \mathrm{mg} / \mathrm{liter}$ ); B, methanol-eluted fraction (concentration $10.30 \mathrm{mg} / \mathrm{liter}$ ); and $\mathrm{C}$, pentane-eluted fraction (concentration $136.8 \mathrm{mg}$ /liter).

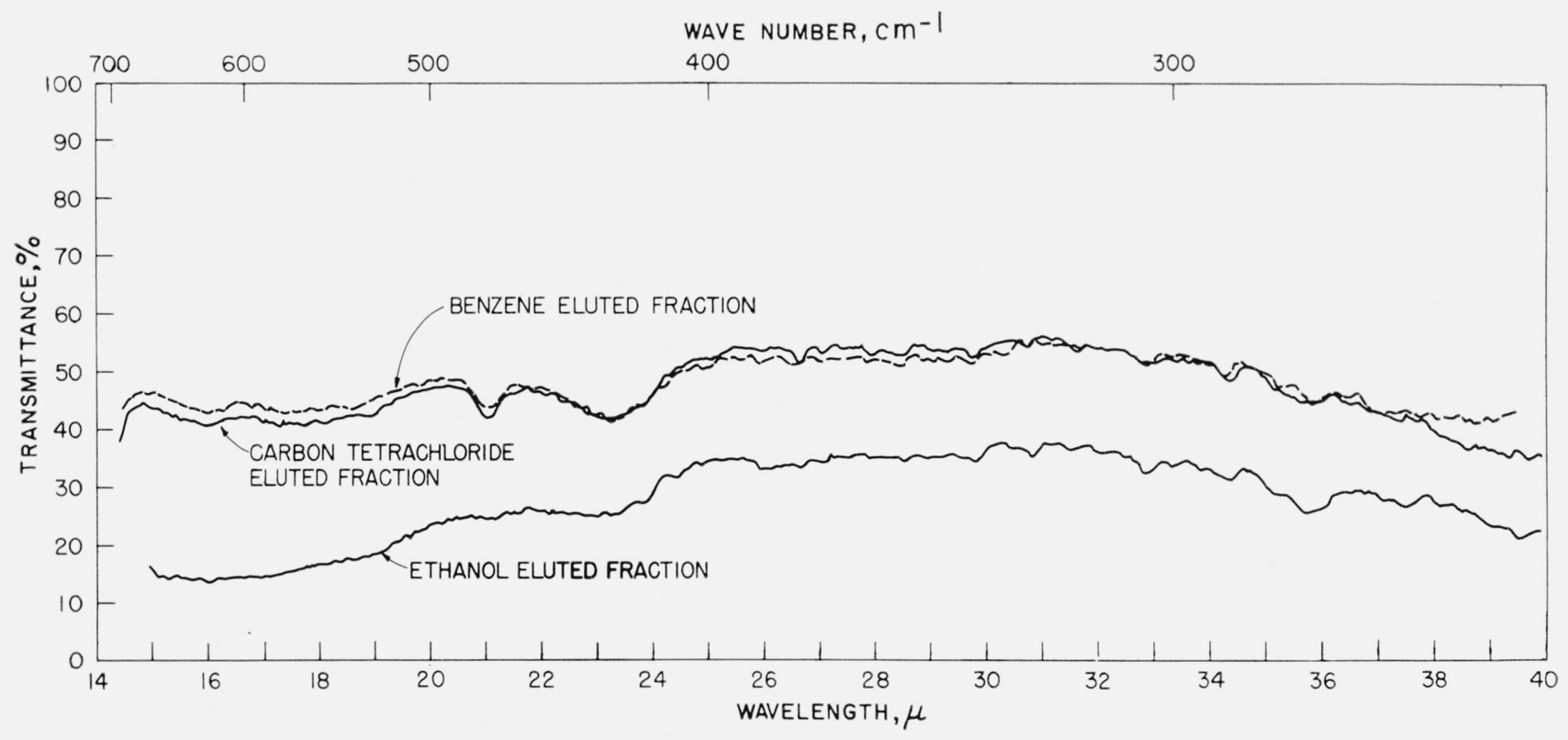

FIGURE 8. Far infrared spectra (15 to $40 \mu$ range) of typical benzene-, carbon tetrachloride-, and ethanol-eluted fractions of oil IV. 


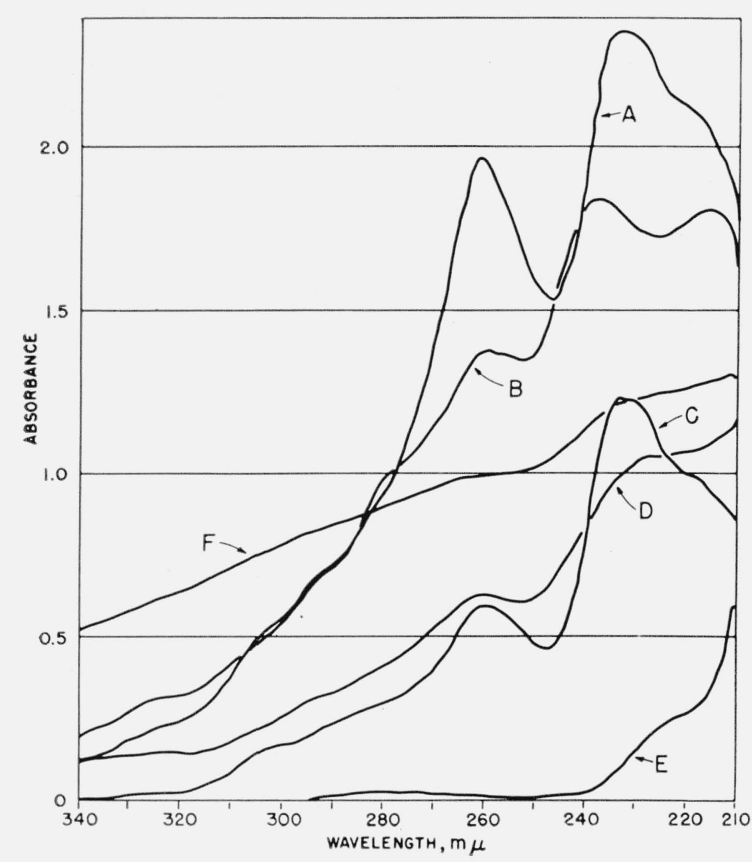

FIGURE 10. Ultraviolet spectra of fractions obtained by acid extraction.

A, First acidaffins, distillate 3 (concentration $12.44 \mathrm{mg} / \mathrm{liter}$ ); B, nitrogen bases, group I, distillate 3 (concentration $12.24 \mathrm{mg} /$ liter); $\mathrm{C}$, second acidaffins, distillate 3 (concentration $6.10 \mathrm{mg} /$ liter); D, nitrogen bases, group II, distillate 3 (concentration $11.44 \mathrm{mg} /$ liter); E, paraffins (a), distillate 3 (concentration $129.6 \mathrm{mg}$ / liter); and F, asphaltenes from crude oil, not air blown, designation AC of Rostler and White [29] (not entirely soluble).

It will be noted that there is a similarity in the mineral-oil fractions separated by the two methods. The acidaffins are similar to the benzene-eluted fraction and also, in this part of the spectrum, to the nitrogen bases and the polar compounds eluted with methanol. A study of the spectra compiled by Friedel and Orchin [10] indicates that the shape of the curves for the acidaffins, nitrogen bases, and benzene- and methanol-eluted portions could result from mixtures of various aromatic and aromatic polar compounds, in agreement with the results of the infrared studies. However, the data of Braude [3] show that conjugated dienes and trienes absorb at 217 and $265 \mu$, respectively. Thus, the possible presence of compounds containing conjugated double bonds along with the aromatic compounds cannot be ruled out. Assuming these absorptions to be largely due to aromatic compounds, the fact that they are more intense in the nitrogen bases, group I, than in the nitrogen bases, group II, is consistent with the conclusion derived from the infrared spectra that the nitrogen bases, group I, are more aromatic. Prem and Duke [21,22], from more extended studies have developed a method of identifying oils in oil-extended rubber. Charlet and his coworkers [6] by means of ultraviolet and infrared studies, have identified specific compound types (aromatic) in fine cuts of gas oil and cycle stock from catalytic cracking.

\section{Quantitative Comparison of Fractions}

In table 5, a quantitative comparison is made of the chromatographic and acid-extraction procedures. The data given here are derived from table 3 . It will be noted that for all six oils, the first pentaneeluted portion is nearly the same in quantity as the paraffin portions. It is also apparent that the combined acidaffins vary from being slightly more than the combined benzene and second pentane-eluted portions in the "paraffinic" oils to considerably less in the highly "aromatic" oils. In oils I, II, and III the two nitrogen-base fractions are roughly equal in quantity to the combined polar fractions, but in the remaining oils the combined nitrogen-base fractions are about twice as large as the combined polar fractions.

TABLE 5. Quantitative comparison of procedures

\begin{tabular}{|c|c|c|c|c|c|c|c|}
\hline & Oil samples & $\begin{array}{l}\text { First } \\
\text { pen- } \\
\text { tane }\end{array}$ & $\begin{array}{l}\text { Par- } \\
\text { affins }\end{array}$ & $\begin{array}{l}\text { Second } \\
\text { pen- } \\
\text { tane } \\
\text { and } \\
\text { ben- } \\
\text { zene }\end{array}$ & $\begin{array}{l}\text { First } \\
\text { and } \\
\text { second } \\
\text { acid- } \\
\text { affins }\end{array}$ & $\begin{array}{l}\text { Car- } \\
\text { bon- } \\
\text { tetra- } \\
\text { chlo- } \\
\text { ride } \\
\text { and } \\
\text { ethanol }\end{array}$ & $\begin{array}{l}\text { Nitro- } \\
\text { gen } \\
\text { bases, } \\
\text { groups } \\
\text { I and } \\
\text { II }\end{array}$ \\
\hline $\begin{array}{l}\text { I } \\
\text { II } \\
\text { III } \\
\text { IV } \\
\text { V } \\
\text { VI }\end{array}$ & $\begin{array}{l}\text { Circosol } 2 \times \mathrm{H} \\
\text { Sundex } 53 \\
\text { SPX 97. } \\
\text { Philrich 5 } \\
\text { Dutrex 20 } \\
\text { Califiux TT. }\end{array}$ & $\begin{array}{r}\% \\
53.4 \\
25.1 \\
26.0 \\
11.0 \\
6.0 \\
10.7\end{array}$ & $\begin{array}{r}\% \\
50.1 \\
23.8 \\
24.5 \\
9.6 \\
6.1 \\
10.5\end{array}$ & $\begin{array}{r}\% \\
43.3 \\
69.7 \\
69.1 \\
81.8 \\
81.8 \\
76.0\end{array}$ & $\begin{array}{c}\% \\
47.7 \\
69.7 \\
67.8 \\
78.0 \\
70.0 \\
68.1\end{array}$ & $\begin{array}{r}\% \\
3.3 \\
6.9 \\
5.8 \\
6.6 \\
11.4 \\
13.2\end{array}$ & $\begin{array}{r}\% \\
2.2 \\
6.5 \\
7.7 \\
12.4 \\
23.9 \\
21.4\end{array}$ \\
\hline
\end{tabular}

The nitrogen-base fractions examined spectroscopically were obtained from an oil high in nitrogen bases and acidaffins. Apparently, a part of the material left behind by the 85 -percent $\mathrm{H}_{2} \mathrm{SO}_{4}$ in the more "paraffinic-type" oils is probably removed by this reagent from the more "aromatic-type" oils. This additional material would tend to mask the characteristics of the polar compounds noted (i. e., acidic groups, etc.) explaining the greater similarity between the acidaffins and the nitrogen-bases studied, than between the benzene-eluted material and the polar compounds. Chemically, most of the polar groups would be expected to be found in the material extracted with 85-percent sulfuric acid. Dunkel, Ford, and McAteer [9] have observed a similar correlation between the quantities of material separated by the acid-extraction method and those separated by their chromatographic procedure. They also observed the same discrepancies between polar compounds and nitrogen bases for oils containing large quantities of nitrogen bases. It may thus be assumed that some of the variations from oil to oil present in the polar fractions are also present in the nitrogen-base fractions but masked in the more highly "aromatic-type" oils. This could be verified, if desired, by an examination of the nitrogenbase fractions from a number of different "paraffinictype" oils. Furthermore, the observed variation in the correlation between the two methods of analysis with change in oil type suggests a variability from oil to oil and of the compounds in both the acidaffin and the nitrogen-base fractions. 
The concentrations of the compounds found in the fractions eluted with the second portion of pentane and with carbon tetrachloride are too small (table 3 ) to affect the spectra of the fractions into which they are separated by the sulfuric-acid extraction procedure.

\section{Summary and Conclusions}

There is a similarity between the paraffin fractions obtained from the oils by the acid-extraction procedure and by the chromatographic method. They contain straight chain, branched, and cyclic hydrocarbons. The benzene-eluted portion and the first and second acidaffins are also similar to each other. Ther contain substituted aromatic compounds possibly joined together by side chains or polynuclear aromatic compounds with side chains, as well as some hydroxyl or amine groups. The nitrogen bases, group I, appear to be composed largely of amines, whereas the nitrogen bases, group II, seems to consist mainly of amides, as well as carbonyls, hydroxyl groups, and ethers. The carbon tetrachloride-eluted portion appears to contain some amines, hydroxyl compounds, amides, and ethers, whereas, in addition to these, the ethanol-eluted portion also contains organic acids. Quantitative comparisons of the two methods indicates the likelihood that compounds whose presence is quite apparent in the ethanol-eluted fraction (mainly acids) are also present in the nitrogen-base fractions, especially the nitrogen bases, group II.

Furthermore, this study indicates a variability of the components in each fraction from one oil to another. From the standpoint of the performance of oil-rubber master batches, this variability appears to be more important in the aromatic and polar materials than in the paraffinic fractions [36, 38]. The polar compounds, such as carbonyls, ethers, amines, and hydroxyl groups, have been found to vary from one oil to another. It is known that compounds such as these can affect the rate of degradation of polymers and may, therefore, account in part for variations in the rate of oven aging reported in laboratory studies [36] for both acidaffins and nitrogen bases obtained from different oils.

It has been suggested by Taft et al. [40] and Rostler and White [29] that active hydrogens on tertiary carbon atoms in the oil fractions might have similar effects. This hypothesis is also consistent with the results of this study because increasing com.plexity of branching and ring structure could naturally lead to a greater number of tertiary carbon atoms differing in activity from oil to oil. It is to be anticipated that this effect would be emphasized in the more complex fractions, such as the acidaffins and nitrogen bases, and especially in the polar materials, where a more marked variation in aromatic ring structure was noted from oil to oil. This effect in these fractions is further enhanced by variations in unsaturated polar groups, such as ketones, acids, amides, etc., which activate the hydrogens on the carbon atom alpha to the unsaturated group.
It has been reported that the rates of oven aging and Banbury breakdown vary for different fractions of the same oil, as well as for different oils [36, 38]. The cause of this behavior is now apparent. For example, paraffins, in spite of their branched character, have been found to retard heat deterioration of master batches [38]. Apparently, the GR-S polymer chain with its unsaturation and conjugation in the phenyl ring contains hydrogens that are more labile than those in the paraffinic portion of the oil. The paraffins thus tend to dilute and protect the more susceptible polymer chains from oxygen attack. Even in the case of polystyrene, Wall, Harvey, and Tryon [41] have shown that oxidative attack occurs on the carbon atom alpha to the phenyl ring.

On the other hand, the more reactive fractions, such as the acidaffins or nitrogen bases, show sufficient evidence of combined polar, aromatic, and saturated structures, so that active centers could be produced upon oxidation. Such centers are apparently more active than those produced on the polymer itself and act as promoters or initiators of free-radical oxidation of the polymer molecule, leading to the observed marked reduction in molecular weight $[36,38]$.

Variations in these polar, aromatic, and saturated structures from oil to oil probably account for observed variations in oven aging and Banbury breakdown for the different oils.

Amines were among the earliest organic accelerators, and their presence in the nitrogen bases, group I, readily explains the effect these fractions have on the rate of cure [38]. The reported increased demand for sulfur in going from paraffins to acidaffins to nitrogen bases [38] is consistent with the increased reactivity of the compounds in these fractions.

Evidence for other groupings of possible interest in these connections, such as $\mathrm{S}-\mathrm{S}, \mathrm{C}-\mathrm{S}, \mathrm{C}=\mathrm{S}, \mathrm{S}-\mathrm{H}$, and aromatic rings containing nitrogen, have not been obtained in this study; bands due to some of them may have been concealed by the strong hydrocarbon absorption.

The authors express their indebtedness to F. S. Rostler of the Golden Bear Oil Co., and to A. R. Glasgow, Jr., D. J. Termini, and L. R. Kleinschmidt of the National Bureau of Standards for supplying the samples and analytical data used in this study, and for continuing constructive discussion of the work. Stimulating and valuable discussions were also held with W. K. Taft of the Government Laboratories, University of Akron. The ultraviolet spectra used in this work were obtained by J. A. Gould of the Bureau.

This work was performed as part of a research project sponsored by the Federal Facilities Corporation, Office of Synthetic Rubber, in connection with the Government Synthetic Rubber program. 


\section{References}

[1] American Petroleum Institute Research Project 44, Catalogue of Infrared Spectral Data.

[2] L. J. Bellamy, The infrared spectra of complex molecules (Methuen and Co., London, 1954).

[3] E. A. Braude, The chemistry society annual reports $\mathbf{4 2}$, 105 (1946)

[4] C. G. Cannon, Nature 1\%1, 308 (1953).

[5] C. G. Cannon and G. B. B. M. Sutherland, Spectrochim. Acta. 4, 373 (1951).

[6] E. M. Charlet, K. P. Lanneau, and F. B. Johnson, Anal. Chem. 26, 861 (1954).

[7] N. B. Colthup, J. Opt. Soc. Am. 40, 397 (1950).

[8] H. Dannenberg, U. Schiedt, and W. Steidel, $\dot{Z}$. Naturforsch. 8b, 269 (1953).

[9] W. L. Dunkel, F. P. Ford, and J. H. McAteer, Ind. Eng. Chem. 46, 578 (1954)

[10] R. A. Friedel and M. Orchin, Ultraviolet spectra of aromatic compounds (John Wiley \& Sons, Inc., New York, N. Y., 1951).

[11] R. A. Friedel and M. G. Pelipetz, J. Opt. Soc. Am. 43, 1051 (1953).

[12] R. A. Friedel and J. A. Queiser, Anal. Chem. 28, 22 (1956).

[13] D. J. Termini and A. R. Glasgow (unpublished).

[14] H. D. Harrington, K. V. Weinstock, N. R. Legge, and E. B. Storey, India Rubber World 124, 435 (1951).

[15] S. H. Hastings, A. T. Watson, R. B. Williams, and J. A. Anderson, Jr., Anal. Chem. 24, 612 (1952).

[16] L. R. Kleinschmidt, J. Research NBS 54, 163 (1955) $\mathrm{RP} 2577$.

[17] L. E. Kuentzel, Spectrum \#604 contributed to the National Research Council, NBS, infrared spectral data program.

[18] S. S. Kurtz, Jr., and C. C. Martin, India Rubber World 126, 495 (1952).

[19] F. A. Miller and C. H. Wilkins, Anal. Chem. 24, 1253 (1952).

[20] M. J. O'Neal, A. Hood, R. J. Clere, M. L. Andre, and C. K. Hines, Proc. Fourth World Petroleum Congress Rome, Section V/C Preprint 3 (1955).

[21] D. Prem and J. Duke, Rubber World 133, 659 (1956).
[22] D. Prem and J. Duke, Rubber World 133, 383 (1955).

[23] H. M. Randall, R. G. Fowler, N. Fuson, and J. R. Dangl, Infrared determination of organic structures (D. Van Nostrand Co., Inc., New York, N. Y., 1949).

[24] F. S. Rostler (private communication).

[25] F. S. Rostler, Rubber Age 71, 223 (1952).

[26] F. S. Rostler, Rubber Age 69, 559 (1951).

[27] F. S. Rostler and H. W. Sternberg, Ind. Eng. Chem. 41, 598 (1949).

[28] F. S. Rostler and R. M. White, Ind. Eng. Chem. 47, 1069 (1955).

[29] F. S. Rostler and R. M. White, Ind. Eng. Chem. 46, 610 (1954)

[30] F. S. Rostler and R. M. White, Rubber Age 70, 735 (1952).

[31] U. Schiedt and H. Reinwein, Z. Naturforsch. $\boldsymbol{7 b}, 270$ (1952).

[32] J. E. Stewart, J. Research NBS 58, 265 (1957) RP 2759.

[33] M. M. Stimson and M. J. O'Donnell, J. Am. Chem. Soc. $\mathbf{7 4 ,} 1805$ (1952).

[34] H. G. Swart, E. S. Pfau, and K. V. Weinstock, India Rubber World 124, 309 (1951).

[35] W. K. Taft, J. Duke, R. W. Laundrie, A. D. Synder, D. C. Prem, and H. Mooney, Ind. Eng. Chem. 46, 396 (1954).

[36] W. K. Taft, J. Duke, A. D. Synder, M. Feldon, and R. W. Laundrie, Ind. Eng. Chem. 45, 1043 (1953).

[37] W. K. Taft, J. Duke, A. D. Snyder, and R. W. Laundrie, Rubber Age $\mathbf{7 5}, 61$ (1954).

[38] W. K. Taft, M. Feldon, J. Duke, R. W. Laundrie, and D. C. Prem, Ind. Eng. Chem. 47, 1077 (1955).

[39] W. K. Taft, R. W. Laundrie, T. B. Harrison, and J. Duke, Rubber Age $\mathbf{7 5}, 223$ (1954).

[40] W. K. Taft, A. D. Snyder, and J. Duke, Rubber Age 75, 838 (1954).

[41] L. A. Wall, M. R. Harvey, and M. Tryon, J. Phys, Chem. 60, 1306 (1956).

[42] K. V. Weinstock, E. B. Storey, and J. S. Sweeley, Ind. Eng. Chem. 45, 1035 (1953).

[43] C. W. Young, R. B. DuVall, and N. Wright, Anal. Chem. 23, 709 (195i).

Washington, August 3, 1956. 